\title{
DIURNAL BEHAVIOR OF AEROSOL OPTICAL PROPERTIES STUDIED WITH LIDAR AND GROUND-BASED INSTRUMENTS Prane Mariel Ong ${ }^{1,2}$, Nofel Lagrosas ${ }^{2}$, Tatsuo Shiina ${ }^{1}$, Hiroaki Kuze ${ }^{1,2}$ \\ ${ }^{1}$ Graduate School of Science and Engineering, Chiba University, 1-33 Yayoi-cho, Inage-ku, Chiba, 263-8522, Japan \\ ${ }^{2}$ Center for Environmental Remote Sensing (CEReS), Chiba University, 1-33 Yayoi-cho, Inage-ku, Chiba 263-8522, Japan \\ *Email: prane.ong@chiba-u.jp
}

\begin{abstract}
The combined use of remote sensing and in-situ monitoring instruments could help improve the assessment of near-surface aerosol properties. In this paper, we analyze the diurnal behavior of aerosol extinction coefficients, $\alpha_{\text {Ext }}(\lambda)$, at $\lambda=349$ and $550 \mathrm{~nm}$ using a lidar and a present weather detector, respectively. We utilize the aerosol optical thickness (AOT), single scattering albedo (SSA), and Ångström exponent (AE) from SKYNET sky radiometer, and AE from aethalometer, and the number distribution from optical particle counter to evaluate the effect of relative humidity (RH) on aerosol extinction coefficients. It is found that although $\alpha_{\operatorname{Ext}}(\lambda)$ often exhibits a positive correlation with the ambient $\mathrm{RH}$, this relation is obscured when both the number distribution and particle size change simultaneously. Moreover, $\alpha_{\text {Ext }}$ at $349 \mathrm{~nm}$ is more sensitive to this change than at $550 \mathrm{~nm}$.
\end{abstract}

\section{INTRODUCTION}

Aerosol plays an important role in the Earth climate change. One parameter that controls visual air quality is the aerosol extinction coefficient. Numerous studies have been performed on relatively higher altitudes, but studies in the near-range are still lacking. In this report, we examine the diurnal behavior of aerosol extinction coefficient by focusing on the lower troposphere where most of the sources and sinks of aerosol are located. The values of aerosol extinction coefficient, $\alpha_{\text {Ext }}(\lambda)$, are derived from a lidar system with a low elevation angle and a visibility meter. Then, they are related to other aerosol optical properties, particle size and number distribution. Synergetic use of the data from these remote sensing and sampling instruments could help improve the assessment of aerosol radiative forcing to climate [1-2].

\section{METHODOLOGY}

A campaign was conducted in the whole month of November 2017 using a near-horizontal lidar system, present weather detector, sky radiometer (SKYNET), aethalometer, optical particle counter, and weather monitor. With these simultaneous measurements, it enables us to investigate the behavior of near-ground aerosol optical properties and particle size. In this paper, we will limit the analysis to the diurnal behavior of aerosols observed under clear and cloudy sky conditions.

Most of the instruments are located on the rooftop of the Faculty of Engineering Research Building in Chiba University in Japan $\left(35.62^{\circ} \mathrm{N}, 140.10^{\circ} \mathrm{E}\right)$, about $65 \mathrm{~m}$ above seal level. The campus is in the urban area of Chiba City, along the east side of the Tokyo Bay.

\subsection{Lidar system}

The lidar system is pointed in the direction of $10^{\circ}$ east of north with an elevation angle of $4^{\circ}$. Although the system is originally a plan position indicator (PPI) lidar that can perform $360^{\circ}$ azimuthal rotation [3], it was operated in a static mode during this November 2017 campaign. Figure 1 shows the schematic diagram of the lidar system. It is based on a diode-laser pumped $\mathrm{Nd}$ :YLF laser emitting at $349 \mathrm{~nm}$ wavelength with $60 \mu \mathrm{J}$ pulse energy and $1 \mathrm{kHz}$ pulse repetition rate. A photomultiplier tube (PMT, Hamamatsu H10304-00$\mathrm{NN}$ ) is used as the receiver sensor. The PMT is connected to a transient recorder (Licel, TR20-160) for data recording of the backscattered signal every $5 \mathrm{~min}$. The obtained data are used to calculate the aerosol extinction coefficient $\left(\alpha_{\text {Ext }}\right)$ using the adaptive slope method [4-5]. This method is used on the premise that a well-mixed layer of aerosol exists below the maximum covered altitude of $350 \mathrm{~m}$ (at $5 \mathrm{~km}$ range).

\subsection{Other Instruments}

Meteorological optical range (MOR) data are routinely obtained every minute using a visibility-meter (Vaisala, PWD52). The measurement is based on the detection of forward scattering at $45^{\circ}$ scattering angle. The visibility, $V$, which is automatically converted by the system to the $550 \mathrm{~nm}$ wavelength equivalent, is used to calculate the aerosol extinction coefficient at $550 \mathrm{~nm}$ using the relation of $\alpha_{\mathrm{Ext}}=\ln (20) / \mathrm{V}$, assuming a contrast ratio of $5 \%$ for the meteorological visibility. 


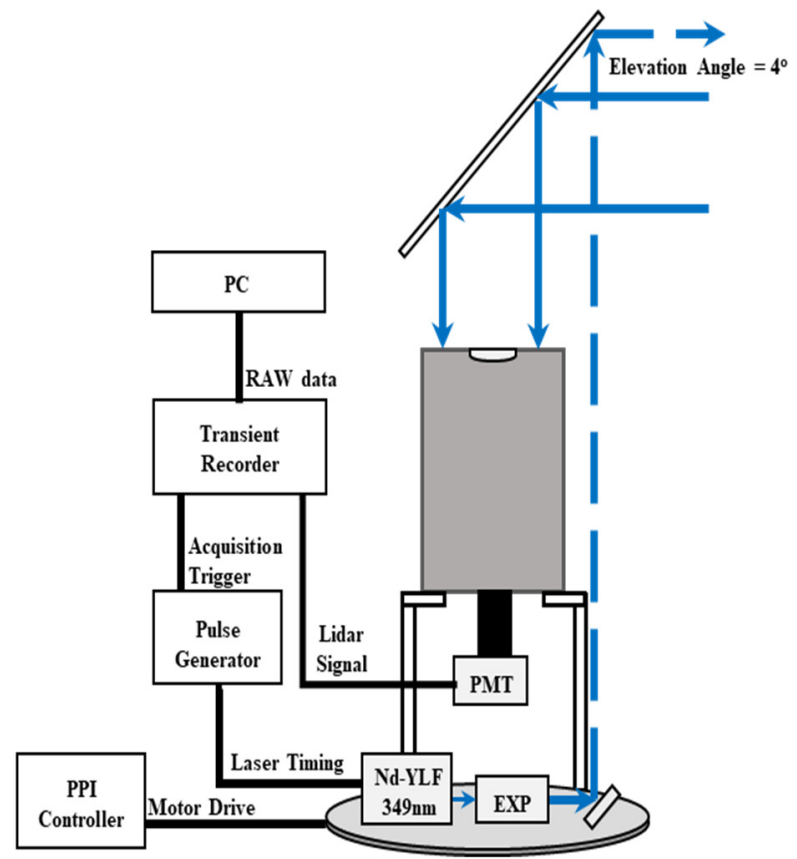

Fig. 1. Schematic diagram of the lidar system.

A ground-based, seven-wavelength sky radiometer (POM-02, Prede) of SKYNET (http://atmos3.cr.chibau.jp/skynet/chiba/chiba.html) is routinely operated on the same rooftop along with the lidar and the PWD52 systems. It measures the intensities of the direct solar irradiance and the diffuse solar radiance distribution. Among its products are the aerosol optical thickness (AOT), the single scattering albedo (SSA) at 340, 380, $400,500,675,870,1020 \mathrm{~nm})$ and the Angström exponent (AE, 400-870 nm). For AOT and SSA, we only consider the wavelengths $340 \mathrm{~nm}$ and $500 \mathrm{~nm}$, which are close to the lidar (349 $\mathrm{nm}$ ) and PWD52 (550 $\mathrm{nm}$ ) wavelengths.

The maximum value of SSA is unity, which indicates pure scattering, while the value less than one represents the contribution of absorption. For 400-870 nm, AE values below $\sim 1.0$ indicate mainly coarse particles (radius, $r>1 \mu \mathrm{m}$ ), while AE values above $\sim 1.5$ indicate mainly fine particles $(r<1 \mu \mathrm{m})$. Fukagawa et al. [5] analyzed the seasonal variation of AOT and AE in Chiba during 1999-2005. They reported that the AOT in winter is relatively small $(<0.2)$, though occasionally the formation of inversion layer leads to air pollution inside the atmospheric boundary layer [6].

Sampling instruments such as an aethalometer (Magee, AE31) and an optical particle counter (OPC; Rion, KC-01E) are also utilized to observe the absorptive property of particles and particle size distributions, respectively. The former is a seven
Table 1. Summary of instruments with their list of products, wavelengths and time resolution.

\begin{tabular}{|c|c|c|c|}
\hline List of Instruments & List of Products & Wavelengths & $\begin{array}{c}\text { Time } \\
\text { Resolution }\end{array}$ \\
\hline $\begin{array}{l}\text { Aethalometer } \\
\text { (Magee AE31) }\end{array}$ & $\begin{array}{l}\text { Equivalent Black Carbon } \\
\text { (EBC) }\end{array}$ & $\begin{array}{l}\mathbf{3 7 0}, 470, \mathbf{5 2 0} \\
590,660,880, \\
950 \mathrm{~nm}\end{array}$ & $5 \mathrm{~min}$ \\
\hline $\begin{array}{l}\text { Aethalometer } \\
\text { (Magee AE31) }\end{array}$ & Ângström Exponent (AE) & $470-880 \mathrm{~nm}$ & $5 \mathrm{~min}$ \\
\hline Lidar & Extinction Coefficient $\left(\alpha_{\mathrm{Ett}}\right)$ & $349 \mathrm{~nm}$ & $5 \mathrm{~min}$ \\
\hline $\begin{array}{l}\text { Present Weather Detector } \\
\text { (PWD52) }\end{array}$ & $\begin{array}{l}\text { Visibility Range, } \\
\text { Extinction Coefficient } \\
\left(\alpha_{E+t}\right)\end{array}$ & $550 \mathrm{~nm}$ & $5 \mathrm{~min}$ \\
\hline $\begin{array}{l}\text { Optical Particle Counter } \\
\text { (OPC, Rion KC-01E) }\end{array}$ & $\begin{array}{l}\text { Count } / \mathrm{L} \text { and } \mathrm{dN} / \mathrm{dln} \mathrm{R} \\
(0.3,0.5,1.0, \mathbf{2 . 0}, \mathbf{5 . 0} \mu \mathrm{m} \\
\text { particle size })\end{array}$ & - & $10 \mathrm{~min}$ \\
\hline $\begin{array}{l}\text { Sky Radiometer } \\
\text { (POM-01, SKYNET) }\end{array}$ & $\begin{array}{l}\text { Aerosol Optical Thickness } \\
(\mathrm{AOT})^{*}\end{array}$ & 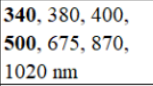 & $10 \mathrm{~min}$ \\
\hline $\begin{array}{l}\text { Sky Radiometer } \\
\text { (POM-01, SKYNET) }\end{array}$ & Ångström Exponent (AE)* & $400-870 \mathrm{~nm}$ & $10 \mathrm{~min}$ \\
\hline $\begin{array}{l}\text { Sky Radiometer } \\
\text { (POM-01, SKYNET) }\end{array}$ & $\begin{array}{l}\text { Single Scattering Albedo } \\
(\mathrm{SSA})^{*}\end{array}$ & $\begin{array}{l}\mathbf{3 4 0}, 380,400, \\
\mathbf{5 0 0}, 675,870, \\
1020 \mathrm{~nm}\end{array}$ & $10 \mathrm{~min}$ \\
\hline $\begin{array}{l}\text { Weather Monitor (Davis } \\
\text { Vantage Pro2) }\end{array}$ & $\begin{array}{l}\text { Relative Humidity }(\mathrm{RH}), \\
\text { Wind Speed and Velocity, } \\
\text { Rain Rate }\end{array}$ & - & $5 \mathrm{~min}$ \\
\hline
\end{tabular}

*in clear sky condition

wavelength (370, 470, 520, 590, 660, 880, $950 \mathrm{~nm})$ aethalometer that measures the elemental black carbon (EBC) concentration, which then is used to estimate the absorption coefficient $\left(\alpha_{\mathrm{Abs}}\right)$ as

$$
\alpha_{\mathrm{Abs}}=\operatorname{EBC}\left(\frac{14625}{c_{r e f} \lambda}\right)
$$

Here, $C_{\text {ref }}(=2.14)$ is the correlation factor due to multiple scattering effects in the fiber filter inside the instrument. For wavelength range between 470 and 880 $\mathrm{nm}$, the AE can be computed using the following linear regression between $\ln \left(\alpha_{\text {Abs }}\right)$ and $\ln (\lambda)$ [7]:

$$
\mathrm{AE}=-\mathrm{d} \ln \left[\alpha_{\mathrm{Abs}}(\lambda)\right] / \mathrm{d} \ln (\lambda) .
$$

The site is also equipped with a weather monitor (Davis, Vantage Pro 2) that constantly measures the ambient weather parameters including temperature, relative humidity $(\mathrm{RH})$, rain rate, wind speed and direction every $5 \mathrm{~min}$. Table 1 summarizes all these instruments with their products and temporal resolutions.

\section{RESULTS AND DISCUSSION}

Figure 2 shows examples of the diurnal variation of aerosol optical properties with respect to a (a) clear sky, and (b) cloudy sky condition observed on November 29 and 20, respectively. On both days, low relative humidity $(\mathrm{RH})$ was observed in mid-afternoon and high $\mathrm{RH}$ in the nighttime to early morning. The AOT values at 340 and $500 \mathrm{~nm}$ were below 0.35 and 0.21 , respectively. In both cases, the wind speed was limited $\left(<2 \mathrm{~m} \cdot \mathrm{s}^{-1}\right)$. 

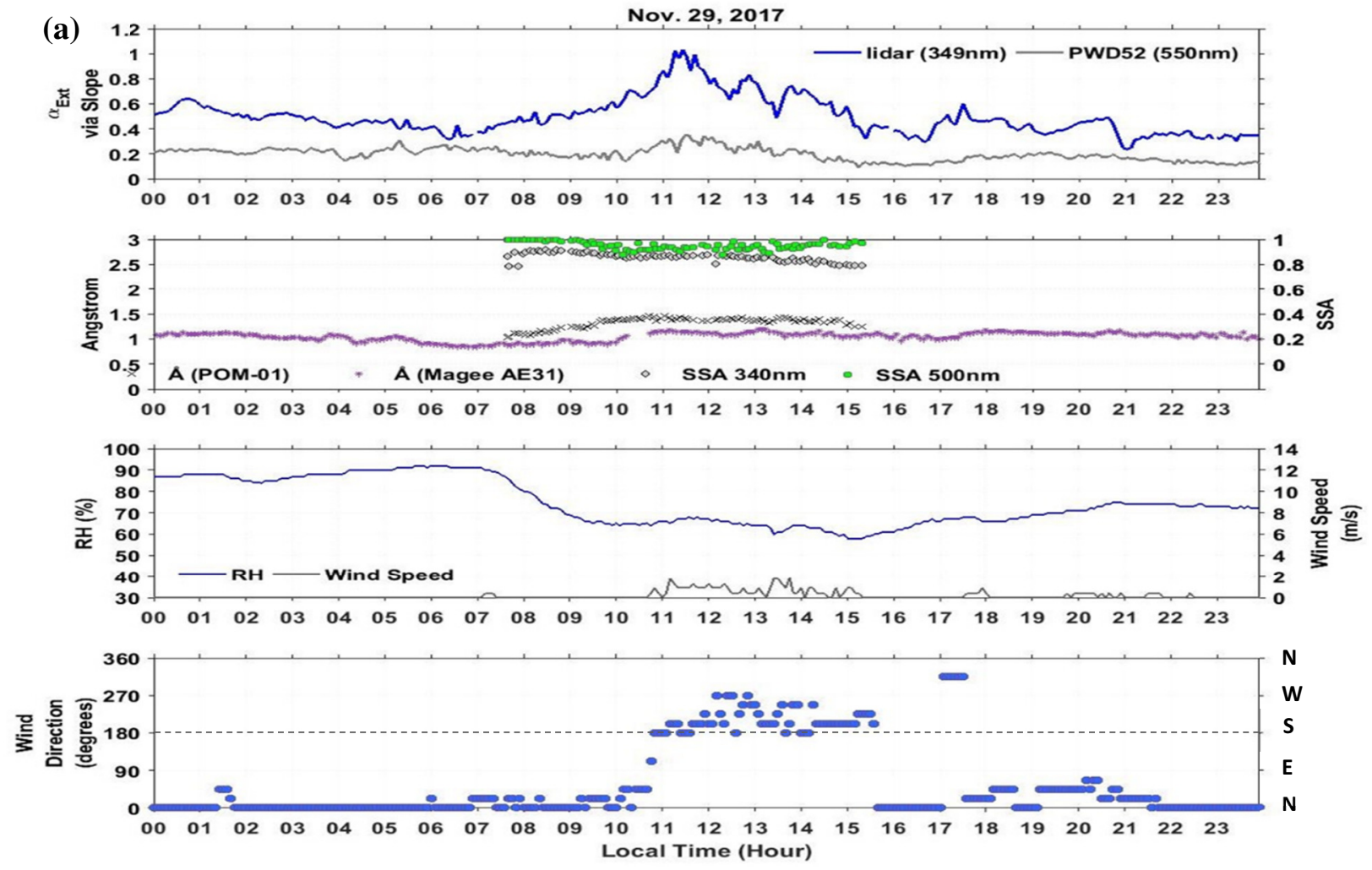

(b)

Nov. 20, 2017
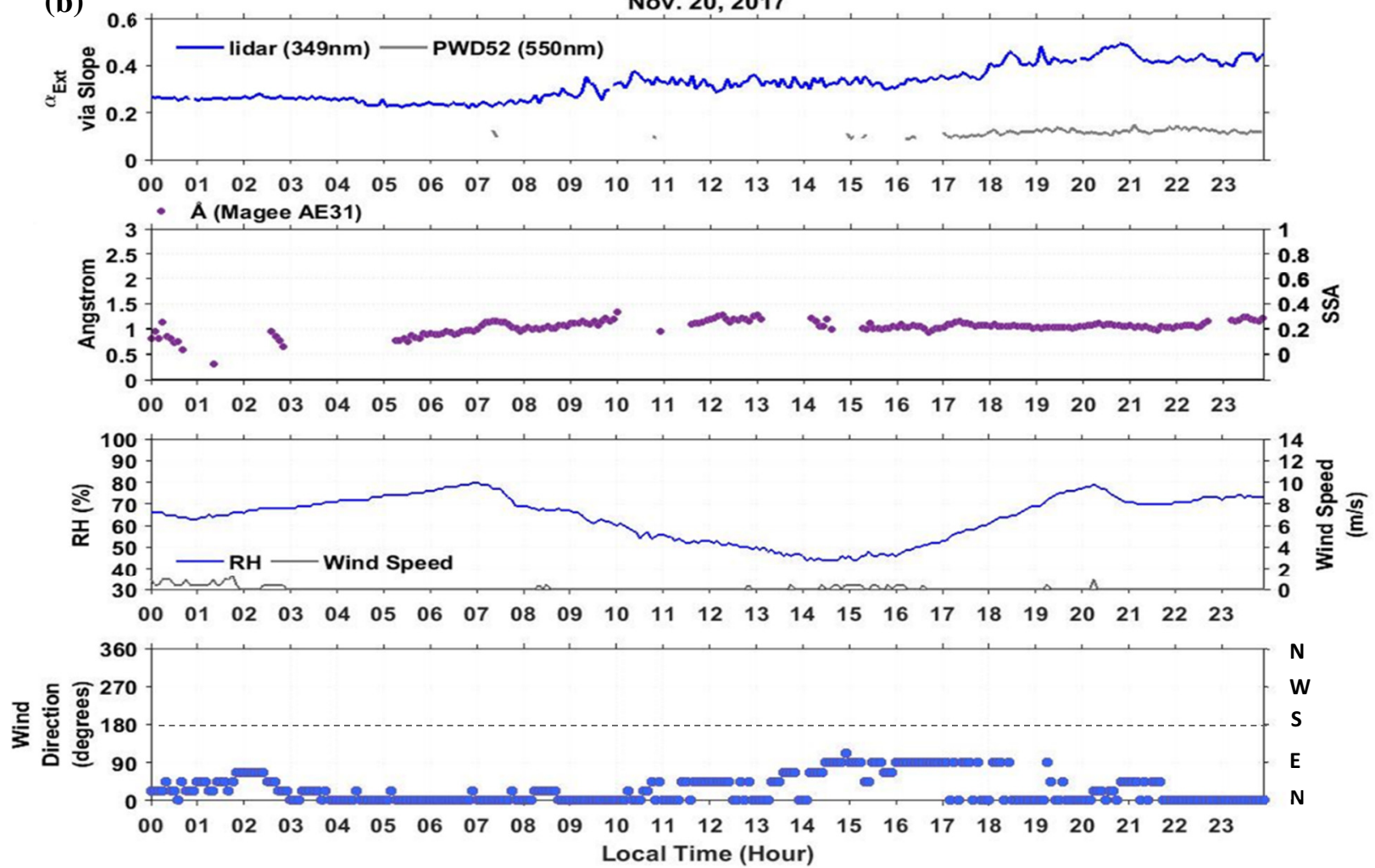

Fig. 2. Example of the diurnal cycle of aerosol optical properties in (a) clear with low visibility sky condition on November 29, and (b) cloudy sky condition on November 20. 


\subsection{Clear Sky (November 29, 2017)}

In the early morning with a constant high RH ( $90 \%)$, a decreasing trend is seen for $\alpha_{\text {Ext,Lidar }}(349 \mathrm{~nm})$, while almost no change in $\alpha_{\mathrm{Ext}, \mathrm{PWD}}(550 \mathrm{~nm})$. From the OPC measurement, on the other hand, there is an apparent decrease in the coarse particles while the fine particles do not vary that much. At around 07:00 JST, as the RH

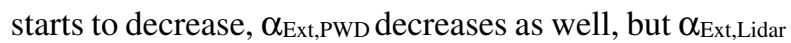
increases. This opposite reaction between the visibilitymeter and lidar data may be attributed to the increase in the $\mathrm{EBC}$ concentration and hence, the increase in $\mathrm{AE}$. Moreover, traffic usually increases in the surrounding area of the measurement site during this time.

Another interesting observation is during the shift in the wind direction from north to south (11:00 JST), resulting in decreases in SSA and AE over time. A decrease of fine particle concentration and constant high concentration of coarse particles are also observed. Although both $\alpha_{\text {Ext,Lidar }}$ and $\alpha_{\text {Ext,PWD }}$ have negative slopes, $\alpha_{\text {Ext,Lidar }}$ is more negatively sloped.

\subsection{Cloudy Sky (November 20, 2017)}

There are no SKYNET products during this day due to the cloud cover. The diurnal cycle of $\alpha_{\text {Ext,Lidar }}$ is almost in-phase with the increase/decrease in RH. The only exception of this trend is around 07:00 JST when a sudden increase of fine particles is observed in conjunction with the onset of the decrease in RH.

Figure 3 shows the change of the $\alpha_{\text {Ext }}$ observed with the lidar $(349 \mathrm{~nm})$ and present-weather detector $(550 \mathrm{~nm})$ plotted against the number concentrations at a geometric mean radius of (a) $0.387 \mu \mathrm{m}$ for fine particles and (b) $3.162 \mu \mathrm{m}$ for coarse particles, both for clean and cloudy conditions. This result also shows that more sensitive change of $\alpha_{\text {Ext }}$ is seen at the UV wavelength, for both fine and coarse particles under both sky conditions.

\section{SUMMARY AND CONCLUSION}

We have derived the aerosol optical properties near the surface region from different instruments and analyzed their relationship. We observed that the change in $\alpha_{E x t}$ is brought about either by the change in the ambient RH, or that in the particle size and number distribution. Moreover, for the cloudy sky condition without the SKYNET products, we can still infer similar observation from aethalometer and OPC. In addition, $\alpha_{\text {Ext }}$ at $349 \mathrm{~nm}$ is more sensitive to this change than at $550 \mathrm{~nm}$. Thus, the present approach based on the nearhorizontal lidar observation will be useful for characterizing near-surface aerosols under cloudy or nighttime conditions, in which the conventional methodology based on the sunphotometer or sky radiometer cannot be undertaken.
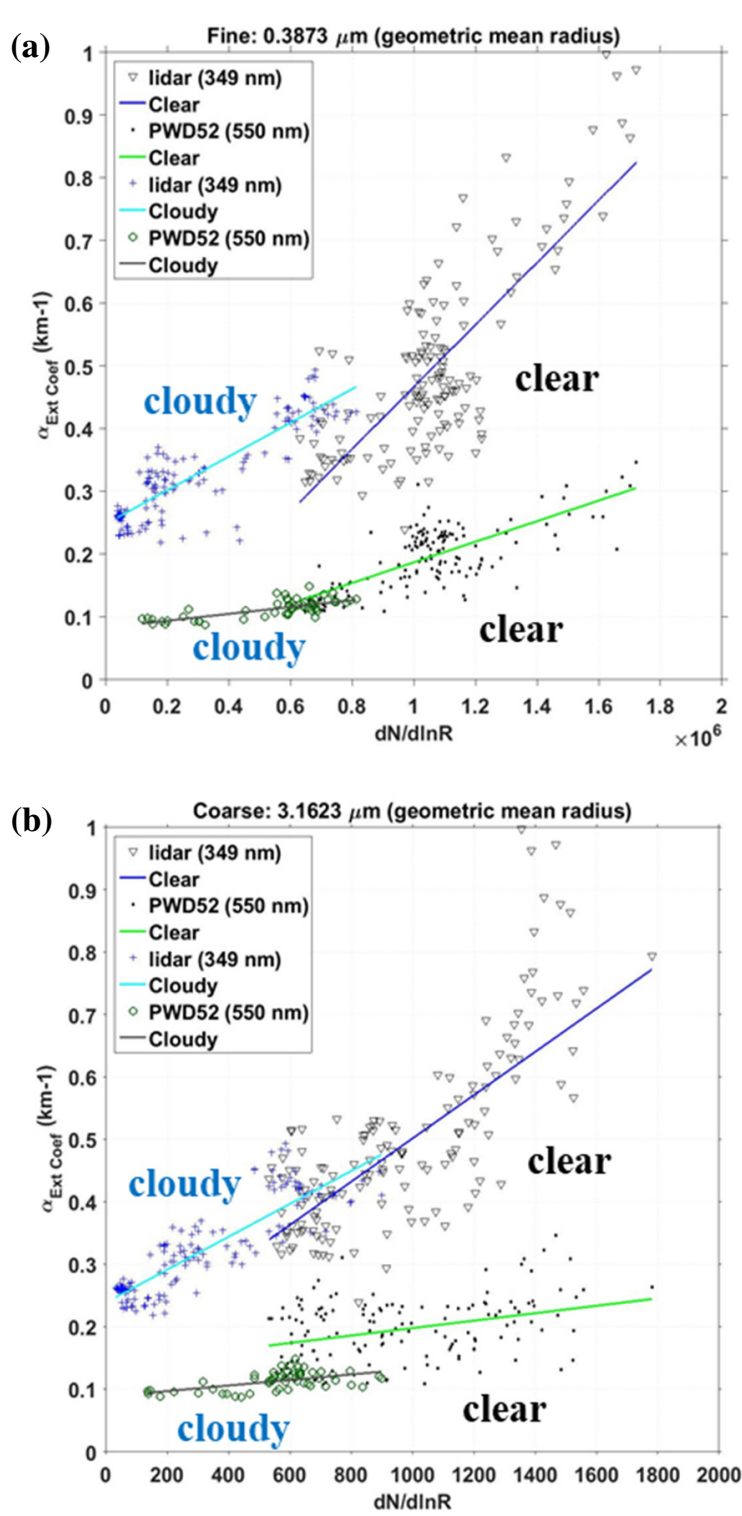

Fig. 3. Extinction coefficient at $349 \mathrm{~nm}$ (lidar) and 550 $\mathrm{nm}$ (PWD52) versus the number concentration (OPC) for (a) fine and (b) coarse particles.

\section{REFERENCES}

[1] IPCC: In: Climate change 2013: The Physical Science Basis, Cambridge, United Kingdom: Cambridge University Press; 2013.

[2] Gebhari, K.A., et al.: Atmos. Environ. 35 pp5177-5191, 2001.

[3] Kamiya, Y., Mabuchi, Y., Haji, S., Saito, H., Bagtasa, G., Manago, N., Irie, H. and Kuze, H., ISRS2013, P1-06 1462, ShinNarashino, May 2013.

[4] Kunz, G.J., and Leeuw G.D., Applied Optics, 32(18) pp32493256, 1993.

[5] Yu-Bing, P., et al., Atmos. Sci. and Oceanic Lett., 7(3) pp203209, 2014.

[6] Fukagawa, S. el al., Atmos. Environ. 40 pp2160-2168, 2006.

[7] Ångström, A., Tellus, Ser. A, 16(1), 64-75, 1964, doi:10.1111/j.2153-3490.1964.tb00144.x. 